\title{
Polyanion binding to cytochrome $c$ probed by resonance Raman spectroscopy
}

\author{
Peter Hildebrandt \\ Max-Planck-Institut für biophysikalische Chemie, Abteilung Spektroskopie, Göttingen (F.R.G.)
}

(Received 19 Decembr 1989)

Key words: Cytochrome $c$; Polyanion binding; Conformational change; Resonance Raman

The interaction of ferricytochrome $c$ with negatively charged heteropolytungstates was studied by resonance Raman spectroscopy. In analogy to previous findings on ferricytochrome $c$ bound to other types of charged interface (Hildebrandt, P. and Stockburger, M. (1989) Biochemistry 28, 6710-6721, 6722-6728), it was shown that in these complexes the conformational states $I$ and II are stabilized. While in state I, the structure is the same as is in the uncomplexed heme protein, in state II three different coordination configurations coexist, i.e., a six-coordinated low-spin, a five-coordinated high-spin and a six-coordinated high-spin form. These configurations constitute thermal coordination equilibria whose thermodynamic properties were determined. The detailed analysis of the low-frequency resonance Raman spectra reveals that in state II the heme pocket assumes an open structure leading to a significantly higher flexibility of the heme group compared to the native ferricytochrome $c$. It is concluded that these structural changes are the result of Coulombic attractions between the polyanions and the lysine residues around the exposed heme edge which destabilize the heme crevice. Modifications of these interactions upon variation of the ionic strength, the $\mathrm{pH}$ or the type of the polytungstate are sensitively reflected by changes of the coordination equilibria in state II as well as of the conformational equilibrium of state I and state II. The conformational changes in state II significantly differ from those associated with the alkaline transition of ferricytochrome $c$. However, there are some structural similarities between the acid form of the heme protein stable below pH 2.5 in aqueous solution and the six-coordinated high-spin configuration of the bound ferricytochrome $c$ at neutral $\mathrm{pH}$ (state II). This suggests that electrostatic interactions with the heteropolytungstates perturb the ionic equilibria of those amino acid side chains which are involved in the acid-induced transition leading to a significant upshift of the apparent $\mathrm{p} \boldsymbol{K}_{\mathrm{a}}$.

\section{Introduction}

Cytochrome $c$ (cyt $c$ ) serves as an electron shuttle in the respiratory chain of aerobic organism, transporting electrons from cytochrome reductase (cyt.red) to cytochrome oxidase (cyt.ox) [1]. Prior to the electron transfer steps, cyt $c$ forms tight complexes with its physio-

\footnotetext{
Abbreviations: cyt $c$, cytochrome $c$; cyt $^{3+}$, ferricytochrome $c$; the indices I and II refer to the conformational states I and II; the index $\mathbf{N}$ indicates the dissolved (uncomplexed) cyt $c$; cyt.ox, cytochrome oxidase; cyt.red, cytochrome reductase; 6cLS, six-coordinated low spin; 6cHS, six-coordinated high spin; 5cHS, five-coordinated high spin; HPT, heteropolytungstates; AsT, $\left(\mathrm{KAs}_{4} \mathrm{~W}_{40} \mathrm{O}_{140}\right)^{27-} ; \mathrm{SiT}$, $\left(\mathrm{SiW}_{11} \mathrm{O}_{39}\right)^{8-}$; RR, resonance Raman; SERR, surface-enhanced resonance Raman; EPR, electron paramagnetic resonance; $C D$, circular dichroism.
}

Correspondence (present address): P. Hildebrandt, Max-Planck-Institut für Strahlenchemie, Stifstr. 34-36, D-4330 Mülheim, F.R.G. logical redox partners via Coulombic attractions between the positively charged lysine-rich front surface of cyt $c$ and the negatively charged binding domains on cyt.red or cyt.ox [2-4]. A variety of experimental and theoretical studies have demonstrated the fundamental importance of electrostatic interactions for the thermodynamics of complex formation and the kinetics of the electron transfer. However, little is known of how these interactions occur on the molecular level. Thus, it is of particular interest to analyze the effect of electrostatic fields on the structural and functional properties of cyt c.

An instructive approach is to study the conformational changes of cyt $c$ bound to negatively charged surfaces such as electrodes, lipid bilayers or polyanions which may mimic the binding domains of its physiological redox partners. In a detailed surface-enhanced resonance Raman (SERR) work it was shown that the interactions of cyt $c$ with the electrical double layer of a metal electrode induce a potential-dependent equi- 
librium between two conformational states [5]. While in state $\mathrm{I}$, the native structure of cyt $c$ is fully preserved and the redox potential is essentially the same as in solution, in state II, the heme pocket is subject to a severe structural rearrangement which leads to the weakening of the axial iron-methionine bond so that a thermal and electric-field dependent coordination equilibrium between a six-coordinated low spin (6cLS) and a five-coordinated high spin ( $5 \mathrm{cHS}$ ) configuration is established. These structural changes are accompanied by a large negative shift of the redox potential which suggests a partial opening of the heme crevice. Employing conventional resonance Raman (RR) spectroscopy, both states I and II could also be observed in complexes formed with anionic phospholipid vesicles [6] and with the fully oxidized cyt.ox [7]. These results indicate that the electric-field-induced conformational changes of cyt $c$ may also occur in vivo and control the physiological redox reactions. Thus the elucidation of the structural changes in state II can be of particular physiological relevance.

In the present RR work, the studies on cyt $c$ bound to charged surfaces were continued using the heteropolytungstates (HPT) $\left(\mathrm{KAs}_{4} \mathrm{~W}_{40} \mathrm{O}_{140}\right)^{27-}$ (AsT) and $\left(\mathrm{SiW}_{11} \mathrm{O}_{39}\right)^{-}(\mathrm{SiT})$. The choice of these model systems was stimulated by a recent work by Chottard et al. [8], who analyzed the optical absorption, circular dichroism (CD), tryptophan fluorescence and electron paramagnetic resonance (EPR) spectra of cyt $c$ complexed by these polyanions. The authors provided evidence for three different forms of cyt $c$ which are stable in the $\mathrm{pH}$ range between 6.5 and 8.5 . It was pointed out that some of their structural and redox properties are comparable with those of the acid, neutral and alkaline forms of cyt $c$, which, in the uncomplexed state, exist at $\mathrm{pH}$ values below 2.5 , around 7.0 and above 10.5 , respectively. On the other hand, preliminary RR experiments of the cyt $c$-AsT complex revealed the formation of the conformational state II in analogy to other model systems [9]. Hence, the question arises if there is a relationship between the intrinsic $\mathrm{pH}$-dependent conformational transitions of cyt $c$ and those induced by external electrostatic fields.

This issue will be addressed in this paper by analyzing the RR spectra of cyt $c$-HPT complexes and of the uncomplexed cyt $c$ measured at different $\mathrm{pH}$ values. The results will be correlated with previous findings obtained by different spectroscopic techniques. Based on a comparison with the SERR spectra of cyt $c$, the molecular description of the conformational changes at charged interfaces will be refined.

\section{Materials and Methods}

\section{Materials}

Horse heart cytochrome $c$ (Sigma, type VI) was purified according to the procedure described by Brautigan et al. [10]. $\left(\mathrm{KAs}_{4} \mathrm{~W}_{40} \mathrm{O}_{140}\right)^{27-}$ and $\left(\mathrm{SiW}_{11}\right.$ $\left.\mathrm{O}_{39}\right)^{8-}$ were prepared according to Refs. 11 and 12 . The preparation of the complexes with ferricytochrome $c$ $\left(\mathrm{cyt}^{3+}\right)$ followed the protocol described by Chottard et al. [8]. In all experiments, the concentrations were 75 $\mu \mathrm{M}$ for AsT (SiT) and $15 \mu \mathrm{M}$ for $\mathrm{cyt}^{3+}$. The absorption spectra of these complexes agreed with the data reported in Ref. 8. All chemicals used in this study were of the highest purity grade available.

\section{Methods}

RR spectra were excited with the $407 \mathrm{~nm}$ line of a $\mathrm{Kr}^{+}$laser using the experimental equipment descriebd in Ref. 9. The laser power at the sample, which was deposited in a rotating cuvette, was attenuated to 25 $\mathrm{mW}$. For temperature-dependent measurements, the cell was placed into a home-built, thermostated chamber which permits temperature control between 2 and $40^{\circ} \mathrm{C}$ with an accuracy of $\pm 1 \mathrm{C}^{\circ}$. The spectral slit width was $2.8 \mathrm{~cm}^{-1}$ in all experiments. SERR spectra were measured from a rotating $\mathrm{Ag}$ electrode as described previ-

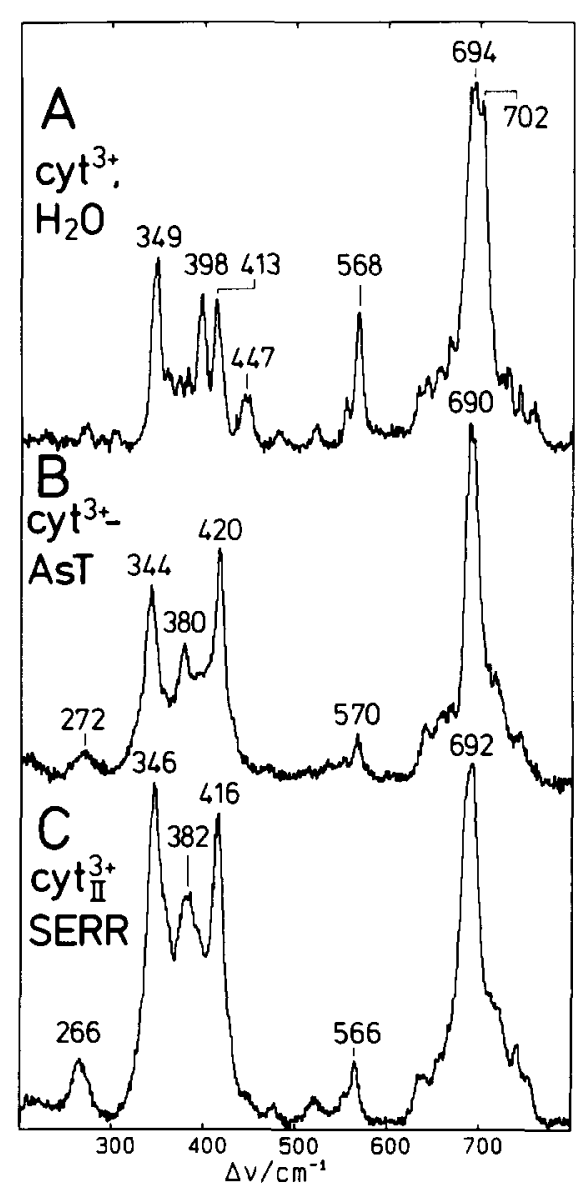

Fig. 1. RR spectra of $\mathrm{cyt}^{3+}$ dissolved in aqueous solution at pH 7.0 (A) and bound to AsT (pH $6.5 ; I \approx 0.001 \mathrm{M}$ ) excited at $406 \mathrm{~nm}$ (B). C is the SERR spectrum of cyt ${ }_{\mathrm{II}}^{3+}$ adsorbed on the Ag electrode at $0.0 \mathrm{~V}$ (vs. SCE) and excited with $413 \mathrm{~nm}$ (see Ref. 5 for further experimental details). 
ously [5]. The RR spectra were analyzed by a band-fitting procedure which is described elsewhere $[5,6]$.

\section{Results and Discussion}

Figs. 1 and 2 compare the RR spectra of $\operatorname{cyt}_{\mathrm{N}}^{3+}$ measured at $\mathrm{pH} 7.0$ in the uncomplexed state (A) and bound to AsT (B) at low ionic strength. Both spectral regions which are displayed provide complementary information about the structure of the heme pocket. The $R R$ bands in the low frequency region, which originate from vibrational modes including high contributions of the peripheral substituents of the porphyrin, can reflect even subtle perturbations of the heme-protein interactions [13-22]. The RR bands in the high frequency region, on the other hand, include the so-called marker bands $\left(\nu_{4}, \nu_{3}, \nu_{2}\right.$ and $\left.\nu_{10}\right)$ whose frequencies are correlated with the oxidation, spin and ligation state of the heme and, hence, can be used to determine the electronic configuration of the heme iron $(13,14,17]$.

In both spectral regions drastic differences are observed between the bound and the uncomplexed $\mathrm{cyt}_{\mathrm{N}}^{3+}$

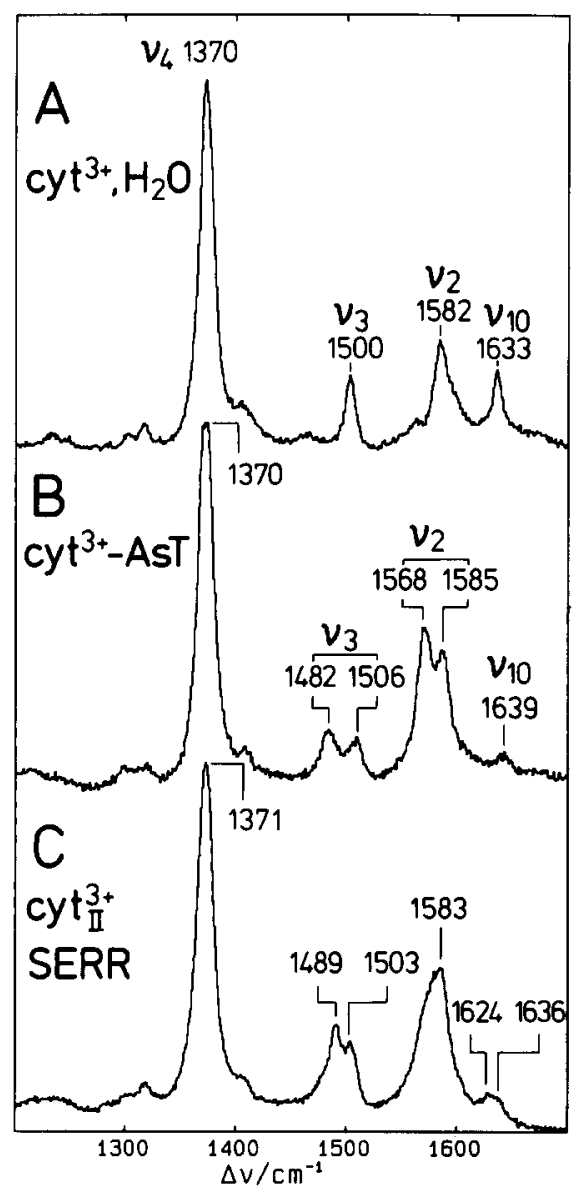

Fig. 2. RR spectra of $\mathrm{cyt}^{3+}$ dissolved in aqueous solution at $\mathrm{pH} 7.0$ (A) and bound to AsT (pH 6.5; I $\approx 0.001 \mathrm{M}$ ) excited at $406 \mathrm{~nm}$ (B). C is the SERR spectrum of $\mathrm{cyt}_{11}^{3+}$ adsorbed on the Ag electrode at $0.0 \mathrm{~V}$ (vs. SCE) and excited with $413 \mathrm{~nm}$ (see Ref. 5 for further experimental details).

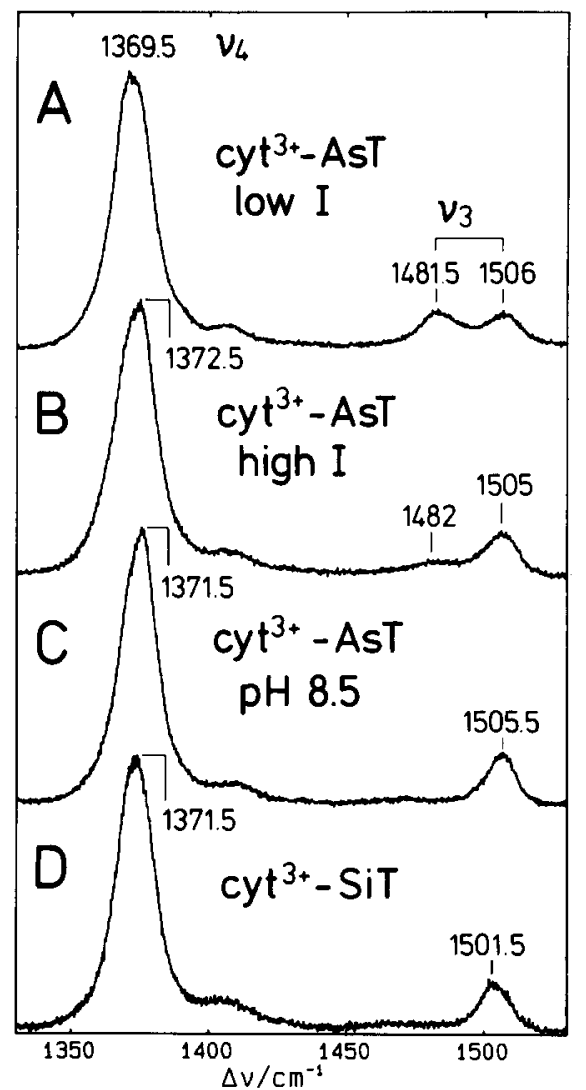

Fig. 3. RR spectra of $\mathrm{cyt}^{3+}$ bound to heteropolytungstates excited at $406 \mathrm{~nm}$. (A), AsT, low ionic strength (approx. $0.001 \mathrm{M}$ ), pH 6.5; (B), AsT, high ionic strength $(0.03 \mathrm{M})$, $\mathrm{pH} 6.5$; $(\mathrm{C})$, AsT, $\mathrm{pH} 8.5(I \approx 0.001$ $\mathrm{M})$; and (D) $\mathrm{SiT}$, pH $6.5(I \approx 0.001 \mathrm{M})$.

which indicates that binding to AsT induces a severe structural rearrangement of the heme pocket including the coordination shell of the iron. While cyt ${ }_{\mathrm{N}}^{3+}$ exhibits a rich vibrational manifold between 250 and $500 \mathrm{~cm}^{-1}$ (Fig. 1A), in cyt ${ }^{3+}$-AsT this region is dominated by three strong peaks (Fig. 1B). In this way the spectrum is closely related to the SERR spectrum of the conformational state II of $\mathrm{cyt}^{3+}\left(\mathrm{cyt}_{1 I}^{3+}\right)$ adsorbed on the $\mathrm{Ag}$ electrode (Fig. 1C). The same analogy is found for the marker band region where, for example, the single band at $1500 \mathrm{~cm}^{-1}$ of $\operatorname{cyt}_{\mathrm{N}}^{3+}\left(\nu_{3}\right.$; Fig. 2A) is replaced by doublets in cyt ${ }^{3+}$-AsT (Fig. 2B) and in cyt II $^{3+}$ (Fig. 2C). The structural changes of cyt ${ }^{3+}$ upon binding to AsT are fully reversible. Dissociation of the complex upon addition of $\mathrm{KCl}$ yields the same $\mathrm{RR}$ spectra of $\mathrm{cyt}_{\mathrm{N}}^{3+}$ as in Figs. $1 \mathrm{~A}$ and $2 \mathrm{~A}$.

\section{Ionic strength and $\mathrm{pH}$ dependence of the conformational changes}

Fig. 3 shows the RR spectra of cyt $_{\mathrm{N}}^{3+}$ bound to SiT and AsT at different ionic strengths and $\mathrm{pH}$ values. According to Chottard et al. [8], under these conditions different forms of the complexed cyt $c$ are stabilized. The spectra display the marker band region $\left(\nu_{4}, \nu_{3}\right)$ which was measured to a high accuracy using $0.2 \mathrm{~cm}^{-1}$ 
step widths. The most pronounced changes are noted for the mode $\nu_{3}$ between 1460 and $1520 \mathrm{~cm}^{-1}$. In cyt $^{3+}$-SiT a single peak with a maximum at $1501.5 \mathrm{~cm}^{-1}$ is observed (Fig. 3D), which shifts to a higher frequency $\left(1505.5 \mathrm{~cm}^{-1}\right.$ ) in cyt ${ }^{3+}$-AsT at pH 8.5 (Fig. 3C). These frequencies imply that there are two different $6 \mathrm{cLS}$ configurations of the bound $\mathrm{cyt}^{3+}$ [17]. Lowering the $\mathrm{pH}$ in solutions of $\mathrm{cyt}^{3+}$-AsT complexes leads to the appearance of a peak below $1490 \mathrm{~cm}^{-1}$ whose relative intensity varies with the ionic strength (Fig. 3A,B). The broad and poorly resolved structure of the peak suggests that it is composed by two bands between 1480 and $1490 \mathrm{~cm}^{-1}$ which would correspond to two HS forms of the heme.

These spectral changes in the $\nu_{3}$ band region are paralleled by frequency shifts and broadening of the peak around $1370 \mathrm{~cm}^{-1}$, indicating that the underlying redistribution among the various conformational states of the bound cyt $c$ is also reflected by the mode $\nu_{4}$.

\section{Identification of the conformational states}

Employing a band-fitting program, the RR spectra in Fig. 3 were analyzed quantitatively. According to the visual inspection of the spectra in the previous section, there are four different species corresponding to four different but overlapping bands in both the $\nu_{4}$ and $\nu_{3}$ band region. A physically reasonable assumption is that the spectral parameters of these bands do not depend on the conformational distribution. This implies that the frequencies $\nu_{\mathrm{i}}$, half-widths $\Delta \nu_{\mathrm{i}}$ and the intensity ratio, $R$, of the $\nu_{4}$ and $\nu_{3}$ bands for each species must be the same in each spectrum. In this way the degrees of freedom in the fitting routine are considerably reduced. Following the protocol of the fitting procedure as it is described in detail in Ref. 6, the iterative analysis yielded spectral parameters for each species which are constant within $\pm 0.2 \mathrm{~cm}^{-1}$ for $\nu_{\mathrm{i}}$ and $\Delta \nu_{\mathrm{i}}$ and $\pm 10 \%$ for $R$ in all spectra. The $\nu_{3}$ band region of the RR spectra analysed in this way are shown in Fig. 4.

Let us first consider the RR spectrum of $\mathrm{cyt}^{3+}$-SiT (Fig. 4D), in which the peak at $1501.5 \mathrm{~cm}^{-1}$ could be resolved into two components at 1499.6 and 1505.7 $\mathrm{cm}^{-1}$ corresponding to two different $6 \mathrm{cLS}$ forms of the bound $\mathrm{cyt}^{3+}$. The same conclusion can be drawn from the analysis of the $\nu_{4}$ band region yielding components at 1369.2 and $1373.7 \mathrm{~cm}^{-1}$. There is no evidence for any contribution of HS configurations in this spectrum. Also, in cyt ${ }^{3+}$-AsT at pH 8.5 (Fig. 4C) both $6 \mathrm{cLS}$ forms clearly prevail; however, now the intensity ratio of both components in the $\nu_{3}$ as well as in the $\nu_{4}$ band region (not shown) is reversed.

The bands of the two low-spin configurations are also present in $\mathrm{cyt}^{3+}$-AsT ar low ionic strength (Fig. 4A); however, in addition, the broad band at approx. $1480 \mathrm{~cm}^{-1}$ can be resolved into two components at 1479.7 and $1487.6 \mathrm{~cm}^{-1}$ whose counterparts in the $\nu_{4}$
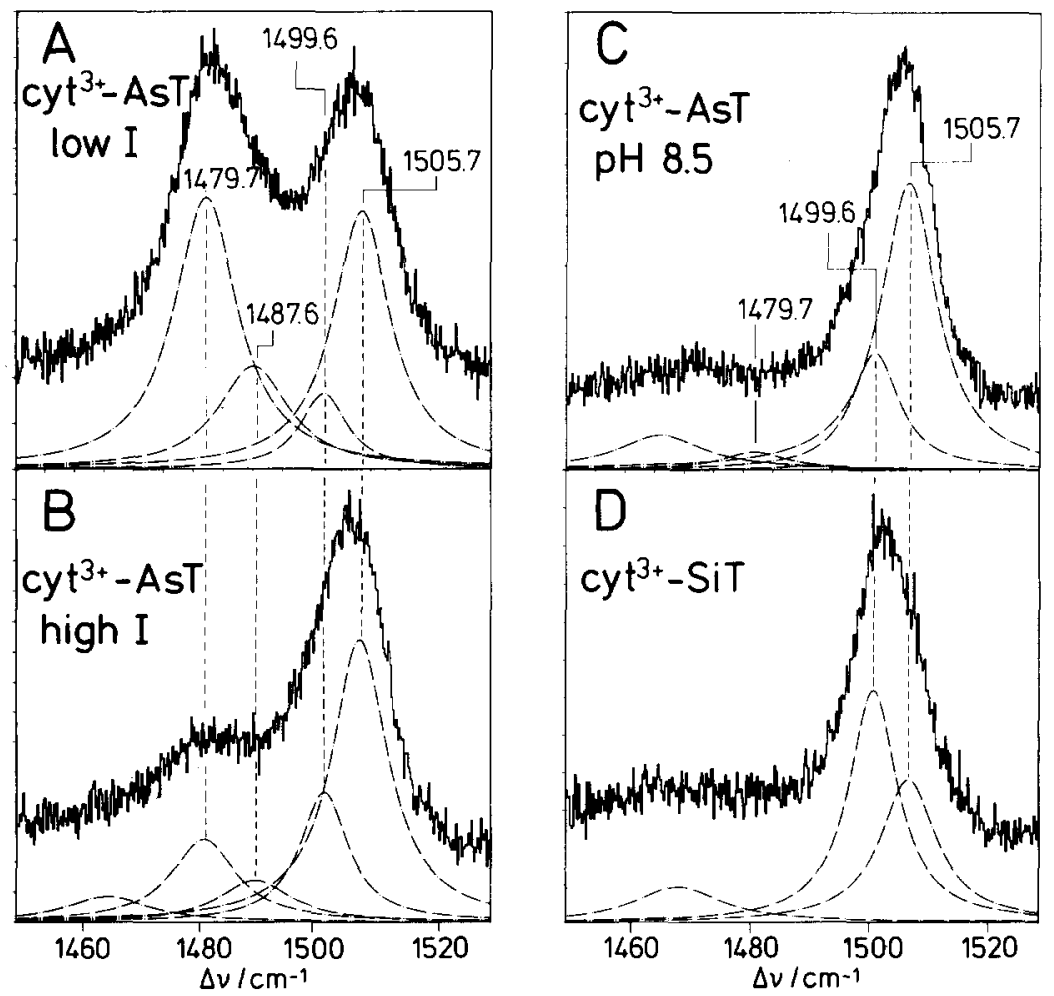

Fig. 4. RR spectra in the $\nu_{3}$ band region of $\mathrm{cyt}^{3+}$ bound to heteropolytungstates excited at $406 \mathrm{~nm}$. (A), AsT, low ionic strength (approx. $0.001 \mathrm{M}$ ), pH 6.5; (B), AsT, high ionic strength (approx. $0.03 \mathrm{M}$ ), pH 6.5; (C), AsT, pH $8.5(I \approx 0.001 \mathrm{M})$; and (D), SiT, pH $6.5(I \approx 0.001 \mathrm{M})$. The dotted lines are the fitted Lorentz profiles (see text for details). 
TABLE I

Marker bands of the various species of ferricytochrome $c$

\begin{tabular}{|c|c|c|c|c|c|}
\hline \multirow[t]{2}{*}{ State } & \multirow[t]{2}{*}{ Complex } & \multicolumn{4}{|l|}{ Mode $^{a}$} \\
\hline & & $\nu_{4}$ & $\Delta \nu_{4}$ & $\nu_{3}$ & $\Delta \nu_{3}$ \\
\hline \multirow[t]{7}{*}{$\mathrm{cyt}_{\mathrm{I}}^{3+} 6 \mathrm{cLS}$} & electrode $^{b}$ & 1369.0 & 12.0 & 1499.5 & 11.4 \\
\hline & HPT $^{c}$ & 1369.2 & 12.8 & 1499.6 & 9.3 \\
\hline & AOT $^{d}$ & - & - & 1499.4 & 10.1 \\
\hline & lipid $^{e}$ & 1369.1 & 12.2 & 1499.4 & 9.6 \\
\hline & phosvitin ${ }^{d}$ & - & - & 1499.8 & 10.1 \\
\hline & cyt. $b_{5}{ }^{\mathrm{d}}$ & - & - & 1499.3 & 9.5 \\
\hline & cyt.ox ${ }^{f}$ & 1368.9 & 11.9 & 1499.7 & 9.6 \\
\hline \multirow[t]{5}{*}{$\mathrm{cyt}_{\mathrm{II}}^{3+} 6 \mathrm{cLS}$} & electrode $^{b}$ & 1373.6 & 13.7 & 1503.1 & 11.6 \\
\hline & $\mathrm{HPT}^{\mathrm{c}}$ & 1373.7 & 13.5 & 1505.7 & 11.0 \\
\hline & AOT ${ }^{d}$ & - & - & 1505.0 & 11.8 \\
\hline & $\operatorname{lipid}^{e}$ & 1374.0 & 13.3 & 1504.6 & 11.1 \\
\hline & cyt.ox ${ }^{f}$ & 1374.3 & 13.0 & 1504.2 & 10.7 \\
\hline \multirow[t]{4}{*}{$\mathrm{cyt}_{\mathrm{II}}^{3+} 5 \mathrm{cHS}$} & electrode ${ }^{b}$ & 1367.8 & 11.8 & 1488.4 & 12.5 \\
\hline & $\mathrm{HPT}^{\mathrm{c}}$ & 1368.3 & 11.6 & 1487.6 & 14.3 \\
\hline & AOT $^{d}$ & - & - & 1490.1 & 15.4 \\
\hline & $\operatorname{lipid}^{e}$ & 1366.0 & 13.4 & 1488.2 & 15.2 \\
\hline \multirow[t]{2}{*}{$\mathrm{cyt}_{\mathrm{II}}^{3+} 6 \mathrm{cHS}$} & electrode $^{b}$ & 1365.4 & 13.3 & 1478.7 & 16.1 \\
\hline & HPT $^{c}$ & 1366.3 & 13.1 & 1479.7 & 12.4 \\
\hline
\end{tabular}

a The frequencies and half-widths of the modes are given in $\mathrm{cm}^{-1}$.

b Adsorbed on the Ag electrode; adopted from Ref. 5.

c HPT, heteropolytungstates.

d AOT, inverted micelles; cyt. $b_{5}$, cytochrome $b_{5}$; all adopted from Ref. 9.

e lipid, phospholipid vesicles; adopted from Ref. 6.

f cyt.ox, cytochrome oxidase; adopted from Ref. 7 .

band region are at 1366.3 and $1368.3 \mathrm{~cm}^{-1}$ (not shown). Following the frequency/core-size correlations the bands at 1479.7 and $1366.3 \mathrm{~cm}^{-1}$ can readily be assigned to a $6 \mathrm{cHS}$ configuration, whereas the other bands are attributed to a $5 \mathrm{cHS}$ state [17]. The relative contributions of both HS forms is reduced upon increasing the ionic strength (Fig. 4B), but they are still clearly higher than in $\mathrm{cyt}^{3+}$-AsT at $\mathrm{pH} 8.5$.

Table I includes the so obtained spectral parameters of the $\nu_{4}$ and $\nu_{3}$ modes of the vairous species as well as those determined for $\mathrm{cyt}^{3+}$ bound to the $\mathrm{Ag}$ electrode and other types of charged interfaces. The comparison confirms the conclusion that binding to HPT induces the formation of the conformational states I (6cLS) and II (6cLS, 5cHS, 6cHS).

Thermal equilibria of the spin and coordination configuration of state II

The RR spectra of cyt ${ }^{3+}$-AsT at low ionic strength were measured at different temperatures in the interval between 4 and $38^{\circ} \mathrm{C}$. It can readily be seen that the relative contributions of the various coordination states are affected by increasing the temperature (Fig. 5). In particular, the $5 \mathrm{cHS}\left(1487.6 \mathrm{~cm}^{-1}\right)$ and the $6 \mathrm{cHS}$ configurations $\left(1479.7 \mathrm{~cm}^{-1}\right)$ increase at the expense of the
6cLS configuration of state II $\left(1505.7 \mathrm{~cm}^{-1}\right)$. On the other hand, the content of state I $\left(1499.6 \mathrm{~cm}^{-1}\right)$ appears to be largely unaffected. From the relative band intensities of the RR spectra at different temperatures, determined by the band fitting analysis, the reaction enthalpies $\Delta H_{\mathrm{R}}$ for the transitions between the various coordination configurations of state II can readily be determined (see Fig. 6). For

$\mathrm{cyt}_{\mathrm{II}}^{3+} 6 \mathrm{cLS} \rightleftarrows \mathrm{cyt}_{\mathrm{II}}^{3+} 5 \mathrm{cHS}$

$\mathrm{cyt}_{11}^{3+} 6 \mathrm{cLS} \rightleftarrows \mathrm{cyt}_{11}^{3+} 6 \mathrm{cHS}$

$\mathrm{cyt}^{3+} 6 \mathrm{cHS} \rightleftarrows \mathrm{cyt}_{11}^{3+} 5 \mathrm{cHS}$

one obtains $\Delta H_{\mathrm{R}}(1)=-6.0 \mathrm{~kJ} / \mathrm{M}, \Delta H_{\mathrm{R}}(2)=-8.9$ $\mathrm{kJ} / \mathrm{M}$ and $\Delta H_{\mathrm{R}}(3)=6.2 \mathrm{~kJ} / \mathrm{M}$, respectively. The determination of the reaction entropies, $\Delta S_{\mathrm{R}}$ requires the knowledge of the relative concentrations, $c_{i}$, of the species $i$ which are related to the relative band intensities $I_{i}$ according to

$c_{i}=f_{i} \cdot I_{i}$

where $f_{i}$ are constants proportional to the Raman cross-sections. These values were determined previously [5,6] so that one obtained $\Delta S_{\mathrm{R}}(1)=-30 \mathrm{eu}, \Delta S_{\mathrm{R}}$ (2) $=-29$ eu and $\Delta S_{\mathrm{R}}(3)=9.9 \mathrm{eu}$, respectively.

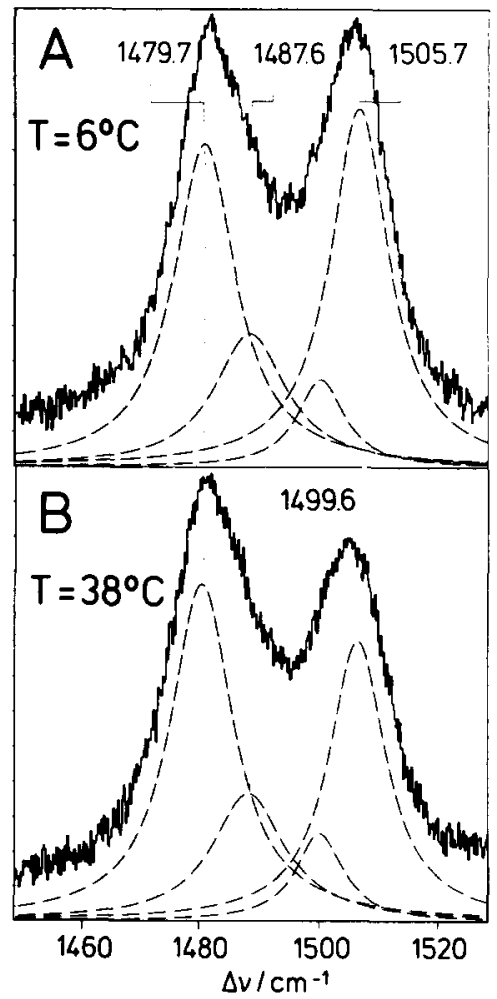

Fig. 5. RR spectra of $\mathrm{cyt}^{3+}$ bound to AsT ( $I$, is approx. $0.001 \mathrm{M}, \mathrm{pH}$ 6.5) measured at $T=6^{\circ} \mathrm{C}(\mathrm{A})$ and $\mathrm{T}=38^{\circ} \mathrm{C}(\mathrm{B})$. The excitation line was $406 \mathrm{~nm}$. The dotted lines are the fitted Lorentz profiles. 


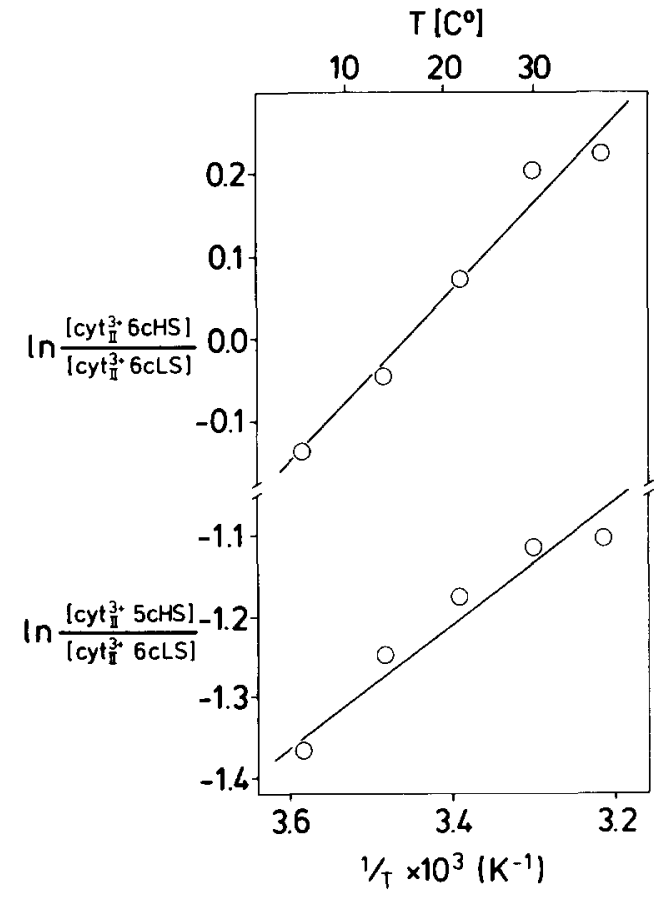

Fig. 6. Van't Hoff plots of the $\mathrm{cyt}_{\mathrm{II}}^{3+} 6 \mathrm{cLS} \rightleftarrows \mathrm{cyt}_{\mathrm{II}}^{3+} 5 \mathrm{cHS}$ and $\mathrm{cyt}_{11}^{3+} 6 \mathrm{cLS} \rightleftarrows \mathrm{cyt}^{3+} 6 \mathrm{cHS}$ equilibria. The concentration ratios were determined from the RR experiments (see text for further details).

Spectral characterization of the various species

For a more detailed structural investigation the pure RR spectra of the various species are required. Such spectra cannot be measured directly but must be obtained by a subtraction procedure based on the measured RR spectra of $\mathrm{cyt}^{3+}$ bound to SiT or AsT at different ionic strengths and $\mathrm{pH}$ values. The appropriate weighting factors for the subtraction procedure can be derived from the computer-fitted spectra in the marker band region (Fig. 4). This method yields pure RR spectra in the entire frequency range of state $I$ and the $6 \mathrm{cLS}$ form of state II. The RR spectra of the $6 \mathrm{cHS}$ and $5 \mathrm{cHS}$ configurations, however, could not be separated from each other since the contributions of these forms relative to each other only varied slightly in the different samples. The discussion of the low frequency spectra of the individual species is based on a tentative assignment of the bands presented in the appendix.

\section{The conformational state I}

Fig. 7C,D displays the RR spectrum of the incomplexed $\mathrm{cyt}_{\mathrm{N}}^{3+}$ in neutral aqueous solution. The lowfrequency region shows an unusually complex vibrational pattern which is in sharp contrast to the $R \mathbf{R}$ spectra of other heme proteins. For example, a band fitting analysis of the RR spectra of met-hemoglobin and ferricytochrome $P-450$ LM2 (spectra not shown here) reveals only five bands in the region between 300 and $420 \mathrm{~cm}^{-1}$ while in the case of $\mathrm{cyt}_{\mathrm{N}}^{3+}$ the number of bands is nearly doubled (Table II). Another peculiarity

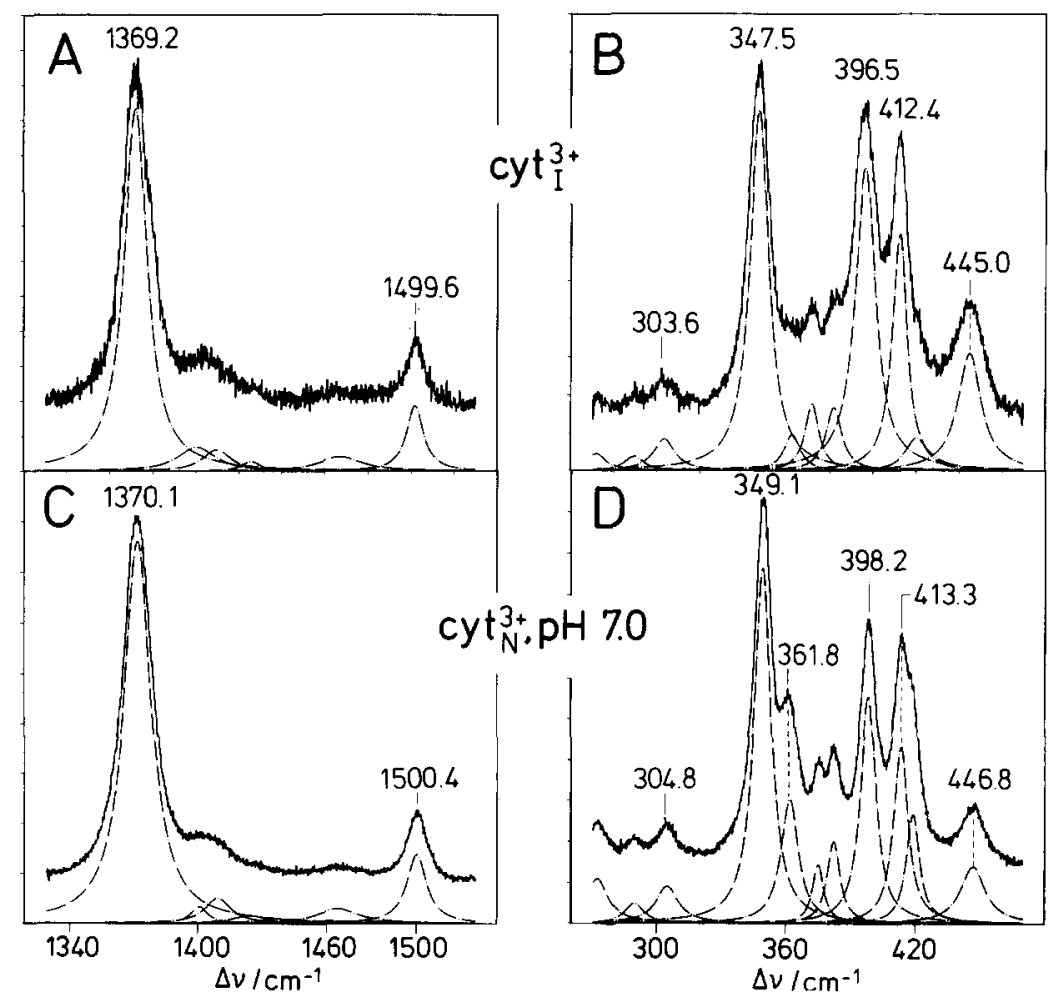

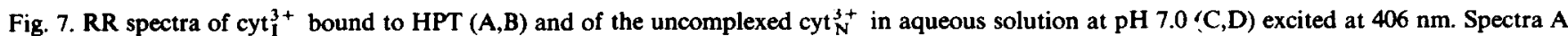
and $B$ were obtained by a subtraction procedure as described in the text. The dotted lines are the fitted Lorentz profiles. 
concerns the half-widths of these bands whose average value is $10.8 \mathrm{~cm}^{-1}$ for ferricytochrome $P-450 \mathrm{LM} 2$ and $13.1 \mathrm{~cm}^{-1}$ for met-hemoglobin but only $8.5 \mathrm{~cm}^{-1}$ for $\mathrm{cyt}_{\mathrm{N}}^{3+}$. These bands result from vibrational modes which include high contributions from the peripheral substituents. Hence, such narrow bands widths indicate that inhomogeneous broadening is very small pointing to a rigid enclosure of the heme in the protein matrix. In fact, the crystal structure of ferri-cytochrome $c$ reveals that the heme is tightly fixed into the heme pocket via a variety of covalent bonds, hydrogen bonding interactions and Van der Waals contacts $[23,24]$. These interactions are sufficiently strong to perturb the porphyrin geometry by tilting the pyrrole rings 2 and 3 , i.e., those rings which carry the thioether linkages to the protein. This geometric distortion of the heme may also provide a reasonable explanation for the large number of bands in this frequency region, since RR-activity can be induced to out-of-plane modes. Furthermore, the rigid fixation in the heme pocket should restrict the mobility of the peripheral substituents of the heme so that individual rotational isomers may be trapped which differ in the orientation of the substituents with respect to the porphyrin plane. Hence, some of the modes which include vibrations of the porphyrin-substituent bonds or internal vibrations of the substituents (i.e., the bands in the fingerprint region) may split (see Appendix).

In Fig. 7 the RR spectra of the uncomplexed $\operatorname{cyt}_{\mathrm{N}}^{3+}$ in neutral aqueous solution and the complexed cyt ${ }_{I}^{3+}$ are compared. In both spectral regions there is a farreaching similarity between both forms. Evidently, in this conformational state the interactions with the polyanion do not affect the structure of the heme and its immediate protein environment. Even the details of the vibrational pattern in the fingerprint region are essentially the same in both spectra (Fig. 7B,D). There are only small frequency shifts of some of the modes in $\mathrm{cyt}_{1}^{3+}$. This can be ascribed to the effect of the electrostatic field, imposed by the array of negative charges of the polyanion, on the vibrational energy levels of the porphyrin of the bound $\mathrm{cyt}^{3+}[5]$.

The magnitude and the direction of this vibrational Stark effect are different for the various modes. For most of the bands, one observes a frequency downshift, in particular for the $A_{\mathrm{lg}}$ fundamentals. Only for a few bands, is an upshift also noted.

As it was shown above, state I prevails after binding of cyt ${ }^{3+}$ to SiT. This complex has been characterized by Chottard et al. [8] employing different spectroscopic techniques. These authors could detect only a small shift of the Soret absorption maximum, but, besides this, provided strong evidence that the native structure is preserved in this state of the bound $\mathrm{cyt}^{3+}$. Again, the shift of the absorption band, which can readily account for the slightly different relative intensities of some of the RR bands in cyt $_{1}^{3+}$, may be ascribed to a Stark effect on the electronic transition [5]. Furthermore, Chottard et al. [8] determined the redox potential of

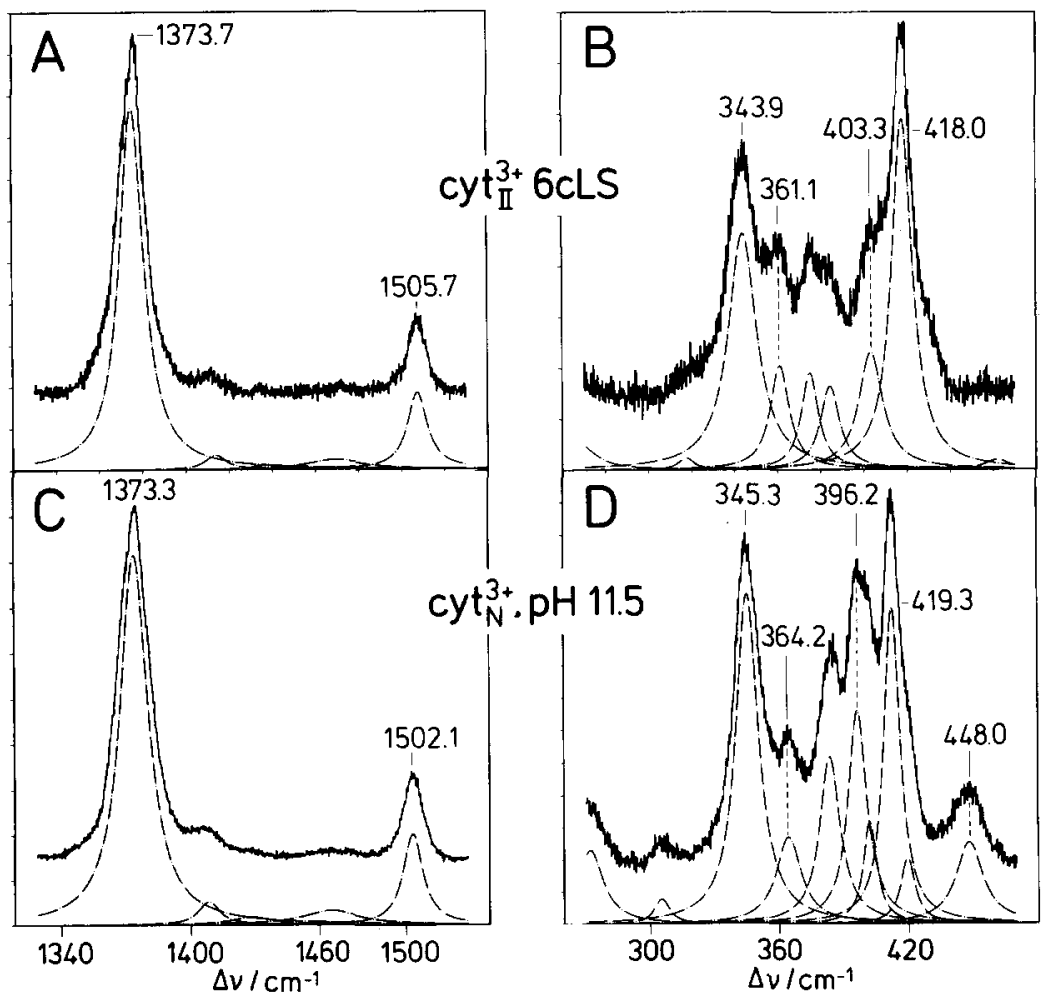

Fig. 8. RR spectra of $\mathrm{cyt}_{\mathrm{II}}^{3+} 6 \mathrm{cLS}$ bound to HPT (A,B) and of the uncomplexed cyt $\mathrm{N}_{\mathrm{N}}^{3+}$ in aqueous solutiuon at pH 11.5 (C,D) excited at $406 \mathrm{~nm}$. Spectra A and B were obtained by a subtraction procedure as described in the text. The dotted lines are the fitted Lorentz profiles. 
+0.05 to $+0.02 \mathrm{~V}$, which is a good agreement with the value obtained from previous SERR studies $(+0.02 \mathrm{~V})$ [5].

\section{The conformational state II}

Compared to state I the RR spectra of the 6cLS configuration of state II reveal significant differences in the entire spectral range (Fig. 8A,B), but there is an excellent agreement with the spectral characteristics of $\mathrm{cyt}_{\mathrm{II}}^{3+} 6 \mathrm{cLS}$ formed in other systems (Tables I and II).

In the low-frequency region, there are dramatic changes of the relative band intensities and significant frequency shifts, in particular, for the bands at 343.9 $\mathrm{cm}^{-1}\left(\nu_{8}\right)$ and $403.3 \mathrm{~cm}^{-1}\left(2 \nu_{9}\right)$. The most striking observation is that the relatively strong band at $\mathbf{4 4 5 . 0}$ $\mathrm{cm}^{-1}$ of state I (Fig. 7B), which is assigned to the propionate bending vibration (see appendix), disappears in state II (Fig. 8B). In state I, two bands (413.3 and $419.0 \mathrm{~cm}^{-1}$ ) were assigned to the combination mode $\nu_{34}+\nu_{35}$ (Table II), but in state II only one band can be detected at $418.0 \mathrm{~cm}^{-1}$ whose half-width is significantly higher (by about $3 \mathrm{~cm}^{-1}$ ) compared to the components of the doublet in state I. A similar band broadening is also observed for the modes $\nu_{8}, 2 \nu_{35}$ and $2 \nu_{9}$. Apparently, the steric constraints by the protein environment, which, in state $I$, force the heme into a rigid conformation, are reduced in cyt $\mathrm{II}_{\mathrm{II}}^{3+} 6 \mathrm{cLS}$ and the rotational barriers of, at least, some of the porphyrin-substituent bonds are lowered. These findings as well as the structural implications derived from other spectroscopic techniques [8] point to an opening of the heme crevice. Such a conformational rearrangement of the heme pocket weakens the iron-methionine bond establishing the thermal coordination equilibrium with the $5 \mathrm{cHS}$ configuration.

In the high frequency region, upshifts of the marker bands point to a considerable contraction of the porphyrin core [17]. It may be that the weakening of the iron-methionine bond leads to a small out-of-plane displacement of the iron towards the histidine-ligand so that an optimum orbital overlap between the iron and the pyrrole nitrogens requires a contraction of the heme core.

Finally, it should be mentioned that the opening of the heme crevice readily explains the large negative shift of the redox potential which was noted for $\mathrm{cyt}_{\mathrm{II}}^{3+} 6 \mathrm{cLS}$ adsorbed on the Ag electrode [5] and in HPT complexes [8].

The interpretation of the RR spectra of the HS forms of state II is more difficult due to the overlapping contributions of both the $5 \mathrm{cHS}$ and the $6 \mathrm{cHS}$ configurations (Fig. 9A,B). While in the marker band region the bands can unambiguously be assigned to the $\nu_{4}$ and $\nu_{3}$ modes of both species (see above) and to the $\nu_{38}$ mode of the $6 \mathrm{cHS}$ form $\left(1512.5 \mathrm{~cm}^{-1}\right)$ [17], the analysis of the fingerprint region is more tentative. Based on a comparison with the RR data of $\mathrm{cyt}_{\mathrm{II}}^{3+} 5 \mathrm{cHS}$ bound to phospholipid vesicles [6], the bands at $342.4,357.0$ and $403.5 \mathrm{~cm}^{-1}$ are attributed to the $5 \mathrm{cHS}$ configuration and assigned to the modes $\nu_{8}, 2 \nu_{35}$ and $2 \nu_{9}$, respectively. Their counterparts for the $6 \mathrm{cHS}$ configuration then can be ascribed to the bands at $330.0\left(\nu_{8}\right), 366.7\left(2 \nu_{35}\right)$ and $393.6 \mathrm{~cm}^{-1}\left(2 \nu_{9}\right)$. The remaining bands cannot be attributed unambiguously to one of these species.

It is evident that the spectral characteristics of state I such as the band at $445.0 \mathrm{~cm}^{-1}$ or the splitting of the combination mode $\nu_{34}+\nu_{35}$ are also missing in both HS

TABLE II

Low-frequency modes of the various species of ferricytochrome $c$

\begin{tabular}{|c|c|c|c|c|c|c|c|}
\hline \multirow[t]{2}{*}{ State } & \multicolumn{7}{|c|}{ Mode $^{\mathbf{a}}$} \\
\hline & $v_{51}$ & $\nu_{8}$ & $2 \nu_{35}$ & pyr tilt ${ }^{b}$ & $2 \nu_{9}$ & $\nu_{34}+\nu_{35}$ & prop bend ${ }^{b}$ \\
\hline $\mathrm{cyt}_{\mathrm{N}}^{3+} 6 \mathrm{cLS} /$ neutral & 304.8 & 349.1 & 361.8 & $375.0 \quad 382.2$ & 398.2 & $413.3 \quad 419.0$ & 446.8 \\
\hline cyt $_{1}^{3+} 6 \mathrm{cLS} /$ lipid $^{c}$ & 304.7 & 348.4 & 361.7 & $372.4 \quad 381.5$ & 397.9 & $413.0 \quad 420.2$ & 446.2 \\
\hline $\mathrm{cyt}_{1}^{3+} 6 \mathrm{cLS} / \mathrm{HPT}^{\mathrm{d}}$ & 303.6 & 347.5 & 362.9 & $372.0 \quad 382.1$ & 396.5 & $412.4 \quad 420.5$ & 445.0 \\
\hline $\operatorname{cyt}_{N}^{3+} 6 \mathrm{cLS} /$ alkaline & 305.2 & 345.3 & 364.2 & 383.5 & $396.2 \quad 401.9$ & $412.4 \quad 419.3$ & 448.0 \\
\hline cyt $^{3+} 6 \mathrm{cLS} /$ lipid $^{\mathrm{c}}$ & 316.5 & 350.4 & 362.3 & $\begin{array}{ll}375.4 & 383.7\end{array}$ & 402.2 & 419.5 & 454.6 \\
\hline cyt $_{11}^{3+} 6 \mathrm{cLS} / \mathrm{HPT}^{\mathrm{d}}$ & 317.3 & 343.9 & 361.1 & $375.1 \quad 384.4$ & 403.3 & 419.5 & 454.6 \\
\hline $\mathrm{cyt}_{11}^{3+} 6 \mathrm{cLS} / \mathrm{HPT}^{\mathrm{d}}$ & 317.3 & 343.9 & 361.1 & $375.1 \quad 384.4$ & 403.3 & 418.0 & 461.7 \\
\hline cyt $_{\text {II }}^{3+} 5 \mathrm{cHS} /$ lipid $^{c}$ & - & 343.1 & 359.9 & $374.0 \quad 387.1$ & 408.1 & 418.5 & 428.0 \\
\hline $\mathrm{cyt}^{3+} 5 \mathrm{cHS} / \mathrm{HPT}{ }^{\mathrm{d}}$ & - & 342.4 & 357.0 & $(378.7)^{\mathrm{e}}$ & 403.5 & $(417.2)^{e}$ & $(432.3)^{e}$ \\
\hline $\mathrm{cyt}_{\mathrm{II}}^{3+} 6 \mathrm{cHS} / \mathrm{HPT}^{\mathrm{d}}$ & - & 330.0 & 366.7 & $(378.7)^{e}$ & 393.6 & $(417.2)^{e}$ & $(432.3)^{e}$ \\
\hline
\end{tabular}

a The frequencies of the modes are given in $\mathrm{cm}^{-1}$; the assignment is discussed in the text.

b 'Pyr tilt' and 'prop bend' denote the pyrrole tilting and propionate bending vibrations, respectively.

c Adopted from Ref. 6.

d HPT, heteropolytungstates.

- Not resolved into the $5 \mathrm{cHS}$ and $6 \mathrm{cHS}$ component. 


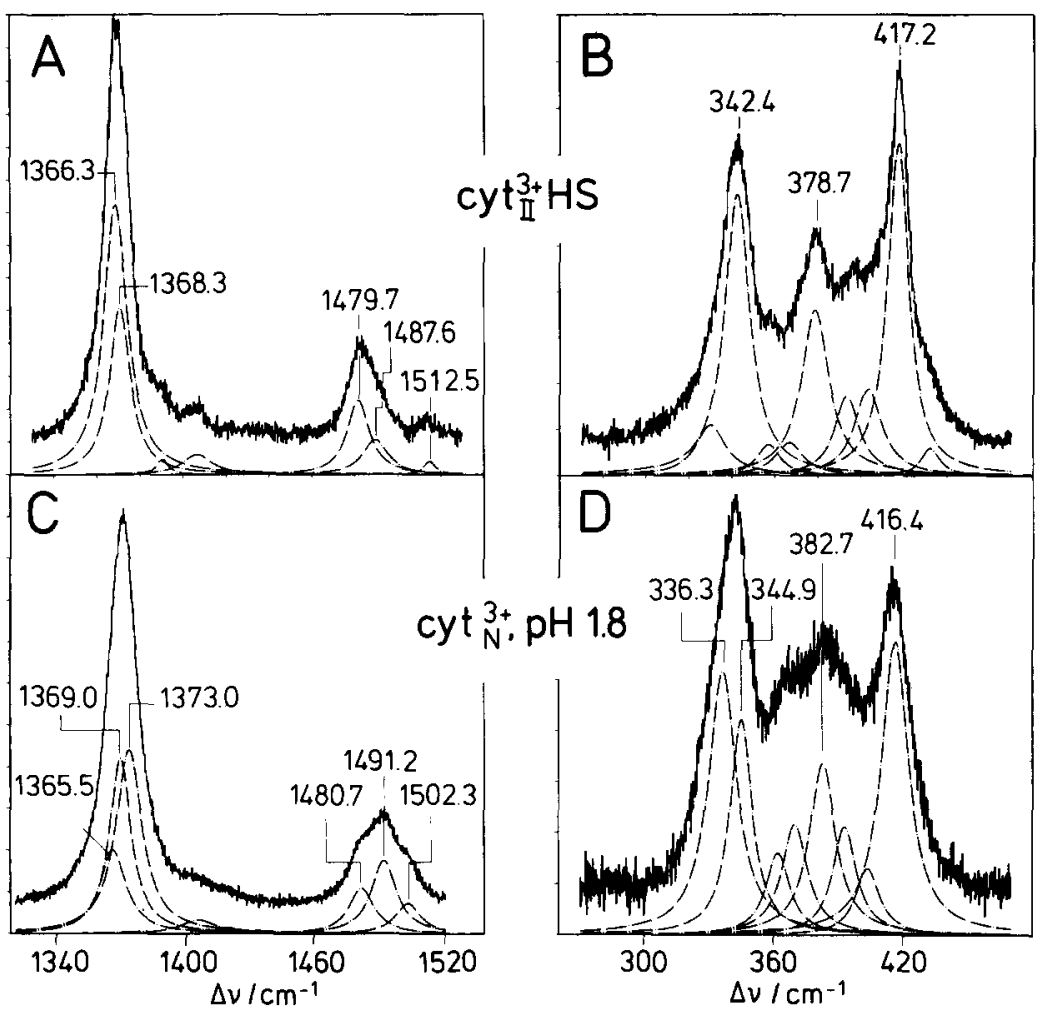

Fig. 9. RR spectra of the 5cHS and 6cHS forms of cyt $\mathrm{II}^{3+}$ bound to HPT (A,B) and of the uncomplexed cyt ${ }_{\mathrm{N}}^{3+}$ in aqueous solution at pH 1.8 (C,D) excited at $406 \mathrm{~nm}$. Spectra A and B were obtained by a subtraction procedure as described in the text. The dotted lines are the fitted Lorentz profiles.

configurations of state II. In addition, the broadening of the bands has further increased compared to $\mathrm{cyt}_{\text {II }}^{3+} 6 \mathrm{cLS}$. The average half-widths of the low frequency bands are even greater than in $\mathrm{cyt}^{3+} 6 \mathrm{cLS}$ establishing the following order: $\mathrm{cyt}_{\mathrm{I}}^{3+}\left(9.8 \mathrm{~cm}^{-1}\right)<\mathrm{cyt}_{\mathrm{II}}^{3+} 6 \mathrm{cLS}(11.0$ $\left.\mathrm{cm}^{-1}\right)<\mathrm{cyt}_{\mathrm{II}}^{3+} 5 \mathrm{cHS}\left(13.5 \mathrm{~cm}^{-1}\right)<\mathrm{cyt}_{\mathrm{II}}^{3+} 6 \mathrm{cHS} \quad(15.4$ $\mathrm{cm}^{-1}$ ). Taking the inhomogeneous broadening of the bands as a measure for the flexibility of the heme in the protein envelope, one can conclude that the heme crevice further opens in the HS forms of state II compared to the $6 \mathrm{cLS}$ form.

\section{Electric-field-and $\mathrm{pH}$-induced conformational changes}

It is well known that in aqueous solution $\mathrm{cyt}_{\mathrm{N}}^{3+}$ is involved in various reversible $\mathrm{pH}$-dependent conformational transformations $[1,25]$. The transitions to the so-called alkaline and acid forms with a $\mathrm{p} K_{1}$ of 9.4 and 2.5 , respectively, include a structural rearrangement of the heme pocket leading to a change of the coordination state. In the alkaline form of the uncomplexed cyt ${ }_{N}^{3+}$, the methionine is replaced by another strong field ligand, most likely Lys-72 or Lys-79, so that a new $6 \mathrm{cLS}$ configuration is established. This is reflected by the frequency upshift of the marker bands compared to the neutral form (Fig. 8C, 7C) (see also Ref. 26-28]. It is assumed that this ligand exchange is accompanied by an opening of the heme crevice implying a major distortion of the heme-protein interactions. However, the low frequency region of the RR spectrum (Fig. 8D) still reveals some striking similarities with the neutral form (Fig. 7D). The number of bands in this region is as high as for $\mathrm{cyt}_{\mathrm{N}}^{3+}$ at $\mathrm{pH} 7.0$ and the average band-widths $\left(10.2 \mathrm{~cm}^{-1}\right)$ is only slightly increased. In addition, the modes $2 \nu_{9}$ and $\nu_{34}+\nu_{35}$ appear at similar frequencies and intensities in both species. Major spectral changes are only associated with $\nu_{8}$, which is shifted down by about $4 \mathrm{~cm}^{-1}$ and whose intensity has decreased, and with the pyrrole tilting for which only one component could be detected. It may be that the structural changes involved in the alkaline transition are restricted only to a part of the heme pocket. In fact, Takano and Dickerson [24] have pointed out that the replacement of the methionine by Lys- 72 or Lys- 79 would require a conformational change in the left part of the heme crevice.

In the acid form of the uncomplexed $\mathrm{cyt}_{\mathrm{N}}^{3+}$ both axial ligands are replaced, accompanied by a major structural rearrangement of the polypeptide chain [1]. Presumably, this process is initiated by the protonation of the histidine ligand, so that the coordination bond to the heme iron is broken [24]. In this way, this residue can no longer stabilize the heme pocket and both axial coordination sites are accupied by weak field ligands, most likely water molecules, leading to a $6 \mathrm{cHS}$ configuration. This is reflected by the frequencies of the marker bands $\nu_{4}$ and $\nu_{3}$ at 1365.5 and $1480.7 \mathrm{~cm}^{-1}$ (Fig. 9C). 
In addition to the $6 \mathrm{cHS}$ configuration, the RR spectrum of the acid form of $\mathrm{cyt}_{\mathrm{N}}^{3+}$ also reveals contributions from a $5 \mathrm{cHS}$ and a $6 \mathrm{cLS}$ configuration as indicated by the $\nu_{3}$ components at $1491.2 \mathrm{~cm}^{-1}$ and 1502.3 $\mathrm{cm}^{-1}$ (Fig. 9C). Following a previous suggestion, the $6 \mathrm{cLS}$ configuration is ascribed to the heme iron coordinated by a water molecule and the counterion (chloride) of the acidifying agent while in the 5cHS configuration, presumably a chloride ion occupies the fifth coordination site [29].

While these conformational changes of the dissolved cyt $_{\mathrm{N}}^{3+}$ in solution are initiated by the protonation respective deprotonation of amino acid side chains, the structural changes in cyt ${ }_{\mathrm{II}}^{3+}$ bound to charged surfaces are induced by electrostatic interactions [5,9]. Table I and II demonstrates that the latter effect does not depend on the material of the surface, since all the characteristic spectral parameters of the individual species are very similar in the various systems.

The binding of cyt $c$ to these surfaces occurs via the positively charged lysine residues around the heme groove. This may lead to the rupture of salt bridges such as Lys-13 - Glu- 90 which, in the uncomplexed cyt $c$, are crucial for stabilizing the closed heme pocket. This implies that the formation of state II, which is based on the destabilization of the heme crevice, requires a specific spatial arrangement of negative charges on the binding domain of the complex partner which permits interactions with the individual lysine residues of cyt $c$, in particular Lys-13. Following these considerations, the various equilibrium concentrations of state I and II in the different HPT systems (see Fig. 4) can be readily understood. Increasing the ionic strength and the $\mathrm{pH}$ in $\mathrm{cyt}^{3+}$-AsT leads to a partial shielding of the opposite charges in the interface of these complexes so that the electrostatic interactions are weakened and the conformational equilibria are shifted towards state I. The significantly lower content of state II in SiT than in AsT at the same ionic strength and pH (Fig. 4) can be attributed to the different sizes of the spherically shaped polyanions although the charge density is about the same for $\mathrm{SiT}$ and AsT. However, only AsT is large enough (approx. $20 \AA$ in diameter [8]) to interact with the entire front surface of $\mathrm{cyt}^{3+}$ [23], while SiT is significantly smaller (approx. $11 \AA$ in diameter [8]) so that the interactions may only partly include Lys-13.

Notwithstanding the fact that the formation of the conformational states I and II is the common property of cyt $c$ in the various electrostatic complexes, Tables I and II reveal deviations for the frequencies and halfwidths within the individual species which are larger than the experimental inaccurary $\left( \pm 0.2 \mathrm{~cm}^{-1}\right)$. These may reflect subtle structural modifications due to the different strengths and directions of the electric fields in the various systems. These spectral deviations are more pronounced in state II, suggesting that the less rigid structure of the heme crevice is more sensitive to changes of the electrostatic interactions than in state I. This may also be the reason why the thermodynamic parameters of the 6cLS-to-5cHS transition in state II (Eqn. 1) are quite different in the various systems. In cyt-HPT complexes, both the reaction enthalpy and the reaction entropy are significantly less negative (by a factor of 3 ) than for state II bound to phospholipid vesicles [6]. On the other hand, for $\mathrm{cyt}_{\mathrm{II}}^{3+}$ adsorbed on colloidal silver $\Delta H_{\mathrm{R}}$ is only $-1.4 \mathrm{~kJ} / \mathrm{M}$ (Hildebrandt, $\mathrm{P}$., unpublished results).

Now the question arises if there is a relationship between both the electric field - and the $\mathrm{pH}$ - induced conformational changes. The RR spectrum of the $6 \mathrm{cLS}$ configuration of state II (Fig. 8A,B) differs significantly from that of the alkaline form of the uncomplexed cyt $_{\mathrm{N}}^{3+}$ (Fig. 8C,D) in both the high- and the lowfrequency region, ruling out any structural similarity with the alkaline form. This conclusion is in line with the CD-, EPR-, and tryptophan-fluorescence data reported by Chottard et al. [8]. Furthermore, the comparison of the RR spectra of these two species with the RR spectrum of the neutral form of cyt $\mathrm{N}_{\mathrm{N}}^{3+}$ (Fig. 7C,D) with respect to the band positions, the splitting of the modes, the half-widths and the relative intensities (see previous section and Table II) indicates that the formation of state II is associated with larger conformational changes than the alkaline transition. For example, the 445.0 $\mathrm{cm}^{-1}$ band of $\mathrm{cyt}_{\mathrm{I}}^{3+}$ which is tentatively assigned to the propionate bending mode, is subject to strong changes in $\mathrm{cyt}_{\mathrm{II}}^{3+} 6 \mathrm{cLS}$ but it is only slightly upshifted in the alkaline form of $\mathrm{cyt}_{\mathrm{N}}^{3+}$. If this assignment is correct, one may conclude that the electric-field-induced structural perturbations are not localized to a part of the front surface but are extended over the entire heme crevice including the hydrogen bonding interactions of the propionate groups.

The comparison of the acid form of $\mathrm{cyt}_{\mathrm{N}}^{3+}$ with the bound $\mathrm{cyt}^{3+}$ must be restricted to the $6 \mathrm{cHS}$ configurations since chloride ions which are involved in the formation of the 5cHS and 6cLS forms at $\mathrm{pH} 1.8$ were not present in AsT containing samples. For the marker bands $\nu_{4}$ and $\nu_{3}$, similar frequencies are noted in the $6 \mathrm{cHS}$ configurations of both species (Fig. 9A,C) and there are also some striking similarities between both species in the low frequency region as far as these bands can unambiguously be attributed to the various spin configurations (see for example the down shift of $\nu_{8}$ below $340 \mathrm{~cm}^{-1}$; Fig. 9B,D, Table II). The comparison of the $6 \mathrm{cHS}$ configurations as well as the fact that the content of the $6 \mathrm{cHS}$ configuration in $\mathrm{cyt}^{3+}$ bound to HPT strongly decreases upon increasing the pH (Fig. 4), suggests that the formation of this coordination state is associated with structural changes similar to the acid transition of the dissolved $\mathrm{cyt}^{3+}$. Again, this view is supported by the study of Chottard et al. [8]. This 


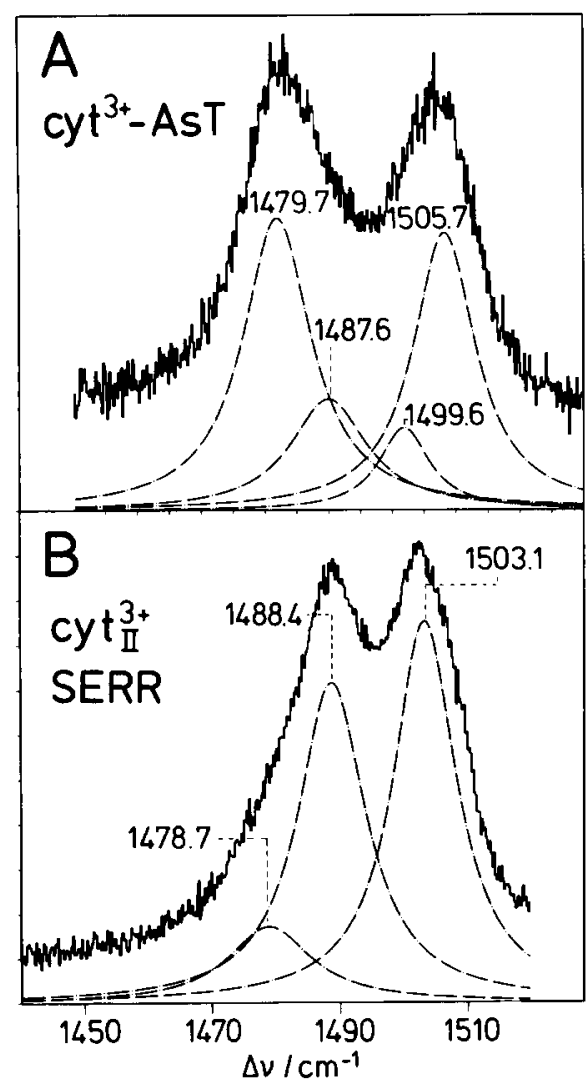

Fig. 10. RR spectrum of $\mathrm{cyt}^{3+}$ bound to AsT ( $I$ approx. $0.001 \mathrm{M} ; \mathrm{pH}$ 6.5) excited at $406 \mathrm{~nm}$ (A) compared with the SERR spectrum of cyt $_{\text {II }}^{3+}$ adsorbed on an $\mathrm{Ag}$ electrode $(0.0 \mathrm{~V}$ vs. SCE) excited at $413 \mathrm{~nm}$ [5]. The dotted lines are the fitted Lorentz profiles.

would imply that binding to HTP shifts the $\mathrm{p} K_{\mathrm{a}}$ of this transition to higher $\mathrm{pH}$ values compared to dissolved cyt $^{3+}$. This surprising behavior is also observed for $\mathrm{cyt}_{\mathrm{II}}^{3+}$ adsorbed on the Ag electrode. Fig. 10B shows such a SERR spectrum measured at $0.0 \mathrm{~V}$ and $\mathrm{pH}$ 7.0. It reveals that as in cyt $^{3+}$-AsT (Fig. 10A) there is a distinct contribution from the $6 \mathrm{cHS}$ configuration ( $\nu_{3}$ at $1478.7 \mathrm{~cm}^{-1}$ ). In both the electrochemical and the HPT complexes, the $6 \mathrm{cHS}$ content does not only depend on the $\mathrm{pH}$, but also on the electrode potential [5] respective the ionic strength and the kind of HPT (Fig. 4). These findings suggest that the electrostatic interaction with the charged surface of the electrode respective of HPT, which stabilize the conformational state II, also faciliate the formation of the acid form of $\mathrm{cyt}^{3+}$. This may be attributed to an effect of the electric field on the ionic equilibria of those amino acid acid-chains which are involved in the acid transition of $\mathrm{cyt}^{3+}$, in particular, the histidine ligand itself [30]. On the electrode at open circuit, an apparent $\mathrm{p} K_{\mathrm{a}}$ of about 4.5 was estimated for the formation of the $6 \mathrm{cHS}$ form which is by about 2 units higher than for the related process in aqueous solution. In the complex with HPT, the $\mathrm{p} K_{\mathrm{a}}$ appears to be even further upshifted.

\section{Conclusions}

The analysis of the RR spectra of cyt $^{3+}$ bound to HPT demonstrates that the main structural changes occur in the heme pocket which is in full agreement with previous conclusions derived from other spectroscopic techniques [8]. It is concluded that the spatial arrangement of the negative charges plays a crucial role for the conformational changes of cyt $c$ bound to HPT or to other types of charged surfaces, in general. This supports the view that in the physiological processes of cyt $c$ the specific topography of the binding surfaces of cyt.red and cyt.ox may control the distribution between the conformational states I and II [9].

\section{Acknowledgements}

The author wishes to express his gratitude to Dr. M. Stockburger for his generous support and helpful discussions. The continuous support and encouragement of Prof. Dr. A. Weller is gratefully acknowledged.

\section{Appendix}

Vibrational assignment of the fingerprint region of cytochrome $c$

The unusual large number of bands in the low frequency $R R$ spectrum of $\operatorname{cyt}_{N}^{3-}$ can be ascribed to two effects which are associated with the specific structure of the heme group in the protein matrix. Firstly, as discussed in the present paper, the rigid enclosure of the heme in the heme crevice restricts the mobility of the substituents so that individual rotational isomers may be trapped. This may lead to a splitting and/or a narrowing of those modes which include high contributions of these substituents. Extremely small band widths (i.e., below $9 \mathrm{~cm}^{-1}$ ) are observed for nearly all the low frequency bands except for the 304.8 and $446.8 \mathrm{~cm}^{-1}$ bands (Fig. 7D). Possible candidates for splitted modes are the doublets at 375.0 and $382.2 \mathrm{~cm}^{-1}$ and at 413.3 and $419.0 \mathrm{~cm}^{-1}$, since they are replaced by single peaks in the alkaline and acid forms of $\mathrm{cyt}_{\mathrm{N}}^{3+}$ (see Table II and Fig. 8D and 9D) in which the heme cervice exhibits a more loose structure [24]. In this context it is interesting to note that the RR spectrum of ferrocytochrome $c$ [5] displays an even higher number of bands in this region and their band widths are smaller than in $\mathrm{cyt}_{\mathrm{N}}^{3+}$. Since in the reduced cyt $c$ the fixation of the heme in the protein is even tighter, this further supports the idea of a conformational heterogeneity of the heme group in cyt $c$.

Secondly, the geometric distortions of the heme and the asymmetric substitution lowers the symmetry of the heme chromophore, so that bands which are Ramanforbidden in the $D_{4 h}$-point group can became $R R$-active [31]. In fact, the crystal structure of tuna $\mathrm{cyt}^{3+}$ and 
cyt $^{2+}$ reveals that the pyrrole rings 2 and 3 which carry the thioether bridges are tilted out of the plane so that the heme group exhibits a more or less ruffled rather than a planar structure. As it was demonstrated by Czernuszewicz et al. [32], a ruffled heme structure leads to a considerable frequency lowering of the spin-state marker bands when compared with a flat geometry. The largest downshifts are noted for the modes $\nu_{19}$ and $\nu_{10}$. Indeed, the spin state marker bands of $\mathrm{cyt}_{\mathrm{N}}^{3+}$ show the same tendency although not that pronounced. The frequencies of $\nu_{3}\left(1500 \mathrm{~cm}^{-1}\right), \nu_{2}\left(1582 \mathrm{~cm}^{-1}\right), \nu_{28}(1467$ $\left.\mathrm{cm}^{-1}\right)$ and $\nu_{11}\left(1563 \mathrm{~cm}^{-1}\right)$ correspond to a core size radius of $1.989 \pm 0.005 \AA$ [17]. Using this value to determine the expected frequencies for the modes $\nu_{19}$ and $\nu_{10}$ one obtaines $1587 \pm 2$ and $1639 \pm 2 \mathrm{~cm}^{-1}$, respectively. The experimental values, however, are clearly lower at 1583 and $1633 \mathrm{~cm}^{-1}$, respectively.

Following these considerations, a tentative assignment of the low frequency bands of cyt $\mathrm{N}_{\mathrm{N}}^{3+}$ (Fig. 7D) is presented based on the recent analysis of the RR spectra of metalloporphyrins $[15,18,22]$. The strongest (polarized) band in this region at $349.1 \mathrm{~cm}^{-1}$ can be attributed to the $A_{\mathrm{lg}}$ mode $\nu_{8}$. In other heme proteins or model compounds, this mode forms a Fermi doublet with the overtone $2 \nu_{35}$ which therefore can be assigned to the band at $361.8 \mathrm{~cm}^{-1}$. The other polarized bands are assigned to the overtone $2 \nu_{9}\left(398.2 \mathrm{~cm}^{-1}\right)$ and to the combination mode $\nu_{34}+\nu_{35}$ (doublet at 413.3 and $419.0 \mathrm{~cm}^{-1}$ ). The band at $304.8 \mathrm{~cm}^{-1}$ may result from the $E_{u}$ mode $\nu_{51}$. No in-plane fundamentals or overtones/combination modes, however, can account for the remaining bands pointing to the involvement of out-of-plane modes. In this context it is interesting to compare the RR spectrum of $\mathrm{cyt}_{\mathrm{N}}^{3+}$ with that of tetragonal nickel octaethylporphyrin crystals in which the porphyrin assumes a ruffled structure, and, hence, bears some structural similarity with the tilted geometry of the heme group in $\mathrm{cyt}^{3+}$ as discussed above. For these crystals, the only out-of-plane modes which were observed upon Soret band excitation are two bands at 360 and $445 \mathrm{~cm}^{-1}$ [22]. Li et al. assigned the $360 \mathrm{~cm}^{-1}$ band to a pyrrole tilting vibration $\left(\gamma_{6}\right)$ which may correspond to the doublet at 375.0 and $382.2 \mathrm{~cm}^{-1}$ in the RR spectrum of $\mathrm{cyt}_{\mathrm{N}}^{3+}$ (Fig. 7D). The $445 \mathrm{~cm}^{-1}$ band was shown to result from a $C_{B} C_{1} C_{2}$ asymmetric bending vibration of the ethyl group. Due to the similar frequency, it is tempting to assign the $446.8 \mathrm{~cm}^{-1}$ band of $\mathrm{cyt}_{\mathrm{N}}^{3+}$ to the same type of mode involving the bending of the propionate side chains. Support for this idea comes from the observation that this band vanishes upon protonation of the propionate groups in the acid form of cyt $c$ (Fig. 9D).

\section{References}

1 Dickerson, R.E. and Timkovich, R. (1975) in The Enzymes (Boyer, P.D., ed.), Vol. XIA, p. 397, 3rd Edn., Academic Press, New York.

2 Rieder, R. and Bosshard, H.R. (1978) J. Biol. Chem. 253, 6054.

3 Smith, H.T., Staudenmayer, N. and Millet, F. (1977) Biochemistry $16,4971$.

4 Koppenol, W.H. and Margoliash, E. (1982) J. Biol. Chem. 257, 4426.

5 Hildebrandt, P. and Stockburger, M. (1989) Biochemistry 28, 6710 .

6 Hildebrandt, P., Heimburg, T. and Marsh, D. (1990) Eur. Biophys. J. 18, 193

7 Hildebrandt, P., Heimburg, T., Marsh, D. and Powell, G.L. (1990) Biochemistry 29, 1661.

8 Chottard, G., Michelon, M., Hervé, M. and Hervé, G. (1987) Biochim. Biophys. Acta 916, 402.

9 Hildebrandt, P. and Stockburger, M. (1989) Biochemistry 28, 6722 .

10 Brautigan, D.L., Ferguson-Miller, S. and Margoliash, E. (1978) Methods Enzymol. 53D, 131.

11 Tézé, A. and Hervé, G. (1977) J. Inorg. Nucl. Chem. 39, 999.

12 Leyrie, M. and Hervé, G. (1978) Nouv. J. Chim. 7, 515.

13 Spiro, T.G. (1983) in The Porphyrins (Lever, A.B.P. and Gray, H.B., eds.), Part II, p. 89, Addison-Wesley, Reading.

14 Kitagawa, T. and Ozaki, Y. (1987) Struct. Bonding 64, 71.

15 Choi, S. and Spiro, T.G. (1983) J. Am. Chem. Soc. 105, 3683.

16 Lee, H., Kitagawa, T., Abe, M., Pandey, R.K., Leung, H-K. and Smith, K.M. (1986) J. Mol. Struct. 146, 329.

17 Parthasarathi, N., Hansen, C., Yamaguchi, S. and Spiro, T.G. (1987) J. Am. Chem. Soc. 109, 3865.

18 Mitchell, M.L., Li, X-Y., Kincaid, J.R. and Spiro, T.G. (1987) J. Phys. Chem. 91, 4690.

19 Abe, M., Kitagawa, T. and Kyogoku, Y. (1978) J. Chem. Phys. 69, 4526.

20 Kitagawa, T., Abe, M. and Ogoshi, H. (1978) J. Chem. Phys. 69, 4516.

21 Desbois, A. and Lutz, M. (1981) Biochim. Biophys. Acta 671, 168.

$22 \mathrm{Li}$, X-Y., Czernuszewicz, R.S., Kincaid, J.R. and Spiro, T.G. (1989) J. Am. Chem. Soc. 111, 7012.

23 Takano, T. and Dickerson, R.E. (1981) J. Mol. Biol. 153, 79.

24 Takano, T. and Dickerson, R.E. (1981) J. Biol. Biol. 153, 95.

25 Theorell, H. and Åkesson, A. (1941) J. Amer. Chem. Soc. 63, 1804.

26 Kitagawa, T., Ozaki, Y., Teraoka, J., Kyogoku, Y. and Tamanaka, T. (1977) Biochim. Biophys. Acta 494, 115.

27 Myer, Y.P., Srivastava, R.B., Kumar, S. amd Raghavendra, K. (1983) J. Prot. Chem. 2, 13.

28 Uno, T., Nishimura, Y. and Tsuboi, M. (1984) Biochemistry 23, 6802.

29 Lanir, A., Yu, N-T. and Felton, R.H. (1979) Biochemistry 18, 1656.

30 Neumann, E. (1981) in Topics in Bioelectrochemistry and Bioenergetics (Milazzo, G., ed.), Vol. IV, p. 113, Wiley, New York.

31 Valance, W.G. and Strekas, T.C. (1982) J. Phys. Chem. 86, 1804.

32 Czernuszewicz, R.S., Li, C.Y. and Spiro, T.G. (1989) J. Am. Chem. Soc. 111, 7024. 